\title{
Castellanos, Terrazas y Ercilla: testimonios histórico-poéticos de la colonia hispanoamericana
}

\author{
Lesly Paola Martelo Acosta \\ leslymartelo552@gmail.com \\ Josué Daniel Herrera Cañate \\ herrera.josue2804@gmail.com \\ Maryandrea Nieto Ávila \\ maryandreanieto97@gmail.com \\ Universidad del Atlántico
}

\section{Resumen}

El descubrimiento de nuevas tierras, las conquistas españolas a los imperios azteca e inca, asesinatos abundantes hacia las comunidades indígenas, esclavitud, vulneración de derechos humanos, violaciones y aberraciones inimaginables, aniquilamientos de pueblos enteros, entre otros factores, marcaron el encuentro entre Europa y América. En este escenario el presente estudio crítico-literario, busca analizar, abordar y profundizar los conceptos inmersos en las poetologías de los autores del periodo colonial hispanoamericano como lo son: el poeta, sacerdote y beneficiado español Juan de Castellanos, el poeta petrarquista novohispano Francisco de Terrazas y el militar, regente y poeta español Alonso de Ercilla.

\section{Palabras clave}

Conquista española; indígenas; esclavitud; Juan de Castellanos; Francisco de Terrazas; Alonso de Ercilla.

Recibido 12/03/20-Aceptado 1/05/20 


\section{Introducción}

El descubrimiento de nuevas tierras, las conquistas españolas a los imperios azteca e inca, sucedió en un espacio temporal de renacimiento para el Viejo Continente que se reinventaba a costa de ocupaciones e invasiones hacia territorios vírgenes en busca de riquezas, metales preciosos y mano de obra a la fuerza, utilizando mecanismos horrendos de dominación y perpetuación de las injusticias que, en consecuencia, dieron buenos resultados a sus economías y formas de vida. En ese sentido, España, en representación de Europa, cumplió el papel de administrador impuesto de los territorios americanos sin ninguna aceptación de los indígenas que los habitaban organizada y pacíficamente, sin restricciones ni razones de peso en materia de discriminación social y racial. De esta manera, muchos europeos llegaron a América en diferentes expediciones para saber y evidenciar cómo era el Nuevo Mundo, a partir de este aspecto, hombres de órdenes religiosas y seglares comenzaron a narrar de forma versificada los acontecimientos en plenas conquistas.

Dentro del marco de estos acontecimientos, en el presente estudio crítico-literario, se analizará, abordará, profundizará y dinamizará los conceptos inmersos en las poetologías de los autores del periodo colonial hispanoamericano como lo son: el poeta, sacerdote y beneficiado español Juan de Castellanos, el poeta petrarquista novohispano Francisco de Terrazas y el militar, regente y poeta español Alonso de Ercilla. Asimismo, se le dará un enfoque al contexto sociocultural de sus obras, un análisis de factores literarios y metalingüísticos, las semejanzas y diferencias entre los tratamientos de los poemas y, concluyendo, la respuesta a la cuestión sobre si las obras en estudio son de carácter histórico, descriptivo, geográfico, etnográfico y romántico en sintonía con su época, sociedad y acontecimientos actuales de los mismos.

\section{Metodología}

Para el presente estudio crítico-literario, se examinaron tres factores para la escogencia de los poemas en cuestión: en primer término, se observó si éstos contenían trascendentalidad, dramatismo y dinamismo; en segundo término, se tuvo en cuenta si el mensaje de cada poema estaba ligado a la contemporaneidad de su época; por último, no se omitió si cada estrofa poseía características históricas, descriptivas, geográficas o románticas. 
Por tanto, después de la evaluación literaria, unánimemente se seleccionaron: el canto VII de la Elegía VI de Elegías de Varones Ilustres de Indias del poeta y beneficiado español Juan de Castellanos, la cuarta parte de Nuevo mundo y conquista del novohispano Francisco de Terrazas y el canto I de La Araucana del español Alonso de Ercilla recogidos en la selección editorial de Raquel Chang-Rodríguez, llamada " Aquí, ninfas del sur, venid ligeras" Voces poéticas virreinales, publicada en 2008. Estos poemas fueron elegidos en virtud de un análisis poético cuidadoso y concreto, llamados por su importancia histórica y cultural en la literatura latinoamericana. Se tuvo en cuenta

\section{Contextos socioculturales de los Poemas}

Como la literatura hace parte de la humanidad y ésta a su vez de la poesía, se concibe el andamiaje imaginativo y potencial de las historias como un marco de referencias hacia el tratado de los análisis contextuales de los poemas. En ese hecho, bajo la consigna de operar integralmente sobre determinada obra en materia épica, lírica e histórica, Cabrera Pons (2015) propone que «la literatura deja de comprenderse como un uso especial... para definirse a partir de ciertas dinámicas socioculturales que tienen una significación particular», todo esto rodeado fundamentalmente de un «contexto específico» (Cabrera, 2015, p. 2), bastión de la poética en sí.

Considerando lo anterior, se propone entonces analizar contextos, tanto sociales como culturales, de los poemas: Elegía VI - Canto VII de las Elegías de Varones Ilustres de Indias del español Juan de Castellanos, Nuevo mundo y conquista (parte 4) del novohispano Francisco de Terrazas y el canto I de La Araucana del militar español Alonso de Ercilla, a continuación:

De acuerdo al canto VII de la Elegía VI, se puede determinar que el contexto, ambiente o entorno del mismo está ligado a los descubrimientos, hallazgos y conocimientos de las islas del Caribe americano en plena etapa de conquista española, administrada y apoderada por el almirante en jefe Juan Ponce de León, cuyo papel en esta empresa de ultramar es decisivo e importante a tal punto de creer que al noreste de lo que hoy se llama Las Bahamas, existía una fuente que concedía en gran manera la eterna juventud a ancianos. Tanto así que, Ponce 
de León a fin de verificar la leyenda, llegó y descubrió Florida con el objetivo intacto de encontrar algún lugar similar al descrito anteriormente.

Por otra parte, analizando a profundidad la cuarta parte del poema Nuevo Mundo y Conquista de Francisco de Terrazas, es de vital importancia anotar que se trata de una historia de amor idílica y transcendental de dos indígenas pertenecientes a la realeza, por ende, todo el andamiaje poético está ubicado dentro del establecimiento de la colonia de Nueva España, configurando así a Quetzal como la Julieta de Tabasco y a Huitzel como el Romeo real de Campeche, en una narración explícita de las desavenencias sociales y estereotipos culturales arraigados en una época en donde el prejuicio moral y las decisiones gubernamentales españolas incidían directamente en los estilos de vida de las personas dominadas. Los personajes principales de este poema se encuentran sometidos y sojuzgados por la zozobra, miedo e incertidumbre de ser arrestados por algunas preferencias ideológicas y, aun así, no se les respetaban sus derechos fundamentales en conjunto con su raza.

Asimismo, la ubicación contextual del canto I de la obra La Araucana (1589) de Alonso de Ercilla es muy dinámica: su ambientación se sitúa en la guerra del Estado de Arauco de Chile, donde los indígenas mapuches (o araucanos) se rebelaron contra las huestes españolas y lucharon a pulso frente a éstas a fin de no dejarse dominar ni gobernar por personas extrañas con ínfulas de superioridad y avaricia. Esencialmente, La Araucana es una radiografía histórica-poética destinada a revelar diferentes factores de la época como los son: las masacres a pueblos indígenas, desplazamientos forzados, arrebatamiento de tierras y violaciones de derechos; pero, aun así, Ercilla resalta la heroicidad y entereza de los naturales del Arauco ante la demarcada destrucción de los extranjeros, por tanto, es la obra fundacional de los hechos ocurridos en Chile -ahora país austral suramericano- y su proceso de asentamiento colonial, los cuales, dejan en evidencia la difícil exasperación que tuvo España en conquistar estas tierras, debido a que contaban con un enemigo hábil y poderoso en técnicas de guerra, además, principalmente anárquico.

Mediante todo lo expuesto, puede englobarse y afirmarse que la situación actual del autor -entorno o ambiente pertinente- es de indispensable atención en correspondencia con los factores de tipo social, político, económico e ideológico que dan como resultado la figura de un contexto específico asociado con el argumento de la obra. Lo anterior es directamente 
proporcional con el ensamblaje de la historia que se provee en Castellanos, Terrazas y Ercilla que, a sabiendas de una estructuración poética de los sucesos expuestos por ellos mismos, cumplen con el hecho de que «la sincronía y diacronía tienen que darse continuamente la mano para dilucidar el objeto literario» (Aguiar e Silva, 1972, p. 409), es decir, tanto los acontecimientos pasados relativos como los específicos se unen para simbolizar la historicidad contextual del poema o de la obra literaria que asimismo concede, a grandes rasgos, la manifestación preceptiva y crítica de la misma en funciones extraliterarias. Ampliando el panorama: Castellanos a partir de la permeabilidad de la fantasía con lo real, efectúa una constitución de acaecimientos verdaderos a la manera del realismo mágico del siglo XX, por su parte, Terrazas ejecuta la sensibilización de una historia de opresión política española que la armoniza con un rasgo romántico de un vínculo de personajes indígenas y, provisionalmente, Ercilla demuestra que las garras sentimentales y emocionales de los nativos chilenos sojuzgaron la maldad del español y su ambición en adquirir tierras a tientas de un abuso histórico. Es claro a simple vista de lo tratado: «el contexto puede ser utilizado para explicar no solo las características del texto, sino también sus méritos cualitativos» (Perkins, 2003, p. 239).

\section{Análisis de aspectos literarios de los poemas}

En esta sección, se analizarán detalladamente los temas, asuntos, envíos poéticos, visiones de mundo, estructuras métricas y figuras literarias de los poemas escogidos, esto con el fin de abordar y extraer los fundamentos poéticos en materia de argumentos contextuales, históricos, económicos, políticos, religiosos y culturales de cada autor y su forma de entender su sociedad a través de los modos de vida y gobierno de la América Latina colonial. Además de esto, se resaltarán las imágenes recurrentes (temas, símbolos o aspectos de una época determinada) de manera general y concisa en pos de un estudio más amplio y sustancial. Entrando en materia, es importante recalcar que no solo es la trascendentalidad de las categorías mencionadas lo que hace previsible un poema, sino el hecho de que éste pueda poseer significaciones coyunturales de tipo personal, social o indistintamente cultural que rijan un conjunto de conceptos propios del poeta. En otras palabras, el poema es digno de contener claves humanas que universalicen tanto el mundo de su autor como el de su lector. Es por ello que es necesario rastrear los pensamientos del poeta para determinar cuán influyente es su obra. 


\section{Castellanos se acerca a lo fantástico-real a través de su Elegía: la aventura de Poncede}

\section{León por una leyenda}

Desde este punto de vista, en la obra Elegía VI - Canto VII: La fuente de la eterna juventud de Juan de Castellanos, compuesta por 7 estrofas, en ejercicio de la técnica de octava real, con rima encadenada consonántica $\mathrm{ABABABCC}$ y versos conformados por 11 sílabas que resultan propiamente en los endecasílabos, relata la llegada de los españoles a las islas del Caribe, tras oír rumores de una fuente encontrada en dicho territorio, la cual permite que los residentes del lugar, recuperaran la juventud que habían perdido. Debido a eso, los conquistadores emprenden un viaje hacia dicha maravilla, para hacerla de su propiedad. Asimismo, la temática representativa del poema se encuentra en la búsqueda por parte de Juan Ponce de León de la legendaria fuente que, según los naturales de las tierras caribeñas, tiene la potestad de devolver la juventud perdida a quienes se bañan o beben de ésta.

De esta manera y atendiendo a la posibilidad de un estado de ánimo implícito del hablante expuesto a tientas de lo tratado en líneas anteriores, se evidencia claramente que en La fuente de la eterna juventud, no hay en sí una demostración emocional del autor Juan de Castellanos, sino por el contrario, una especie de exposición histórico-geográfica sobre la situación que se presenta al ser descubierta una leyenda amerindia antiquísima, y por la cual el conquistador Ponce de León accede a creerla. En ese sentido, Castellanos configura su accionar poético a través de la narración casi mitológica de un lugar con poderes sobrenaturales, dejándole al lector el discernimiento de inferir, interpretar y captar su extensa objetividad frente a un tema propiamente misterioso. No objetando estos aspectos, el poema en sí no conlleva un relato de tipo subjetivo que se relacione con alguna visión de mundo preexistente, pero no hay ninguna duda de que Castellanos plasmará en su obra ciertos rasgos característicos de su opinión, percepción e historicidad de su sociedad.

De ahí precisamente, se puede afirmar que Castellanos se muestra en la Elegía VI como un explorador histórico-anunciativo de un suceso lleno de misticismo, naturalismo y costumbrismo que se relaciona con las creencias indígenas referentes al milagroso rejuvenecimiento proveniente de un lugar paradisíaco, cuya función no connota una interpretación personal del autor, pero sí una mirada objetiva y encaminada a la admiración que se tuvo sobre esta espectacular leyenda, bien puede denominarse dramática, informativa 
y posiblemente veraz. Incluso así, Castellanos no agrega su perspectiva con respecto al asunto, gracias a la trascendencia que tiene la fuente de la eterna juventud como un rumor mítico precolombino, por ende, su papel es dar a conocer su mundo.

No obstante, lo mencionado anteriormente no completa todo, hay un panorama más revelador: aunque en La fuente de la eterna juventud, el poeta Juan de Castellanos no comenta nada acerca del hecho narrado, es evidente que en todo el canto está exponiendo un suceso histórico de mayor calibre y pertenece a la interpretación universal de la sociedad que procede de él. Al decir: «yo estoy agora considerando según la vanidad de nuestros días...» (ChangRodríguez, 2008, p. 125), no está enjuiciando o dando un criterio participativo al acontecimiento, sino reflexionando sobre cómo probablemente ese tiempo no era tan próspero, ello, lo argumenta la frase «la vanidad de nuestros días» (Chang-Rodríguez, 2008, p. 125), la cual determina que en esa época la búsqueda de lo material primaba en lugar del progreso. Por ello, no es tanto comprender si hay una opinión de Castellanos, es saber que él propone una mirada concreta de lo que probablemente vivió, escuchó o presenció, en virtud de dejar un testimonio.

A partir de lo ulterior y dentro de todo este marco explicativo, una figura literaria que juega como papel principal de proposición universal del poema e inclusive ayudante de la significación de la Elegía IV, es la personificación, cuya tarea a simple vista es representar una abstracción en el hecho de una persona y en La fuente de la eterna juventud se puede observar en tres ocasiones: primero, cuando Castellanos le atañe la cualidad de prepotente a un objeto inanimado como en «isla prepotente» (Chang-Rodríguez, 2008, p. 125); segundo, cuando el poeta español decide añadirle un adjetivo a una palabra idealizada como se puede ver en la frase «loca fantasía» (Chang-Rodríguez, 2008, p. 125) y, tercero, cuando realiza tres repeticiones adjetivales: «cuán rica, cuán pujante, cuán potente» (Chang-Rodríguez, 2008, p. 125), refiriéndose totalmente a un territorio. De esta manera, el personificar factores inanimados hace que el poema se convierta en un boom literario que facilita el entendimiento de los sucesos ocurridos en aras de versificarlos y darlos a conocer como una descripción un tanto real como fantástica.

Ante todo lo expuesto, no cabe duda que en La fuente de la eterna juventud se demuestra la formalidad y nivel de cultura del autor, debido a su gran garaje léxico y semántico, también utiliza, como lo era usual en su época, una economía lingüística que da comodidad a la 
conformación de los versos y asimila algunas palabras con el mismo fin. Por otro lado, se apropia de un discurso influenciado por la mitología que era costumbre de los habitantes nativos de la Bímini, en tanto que esto no aplica textualmente una temporalidad de los hechos, sino que lleva una secuencia implícita de los mismos de manera crítica.

\section{El amor indígena real y el antagonismo de los españoles expuestos por Terrazas: simbiosis de la historia y el romanticismo}

Ahora bien, procediendo de la misma forma a analizar la cuarta parte de Nuevo mundo y conquista de Francisco de Terrazas. Ésta, cuya estructura está compuesta por 25 estrofas, con empleo de la técnica de octava real, rima encadenada consonántica ABABABCC, versos conformados por 11 sílabas (endecasílabos), y en la que de igual manera, se pudo hallar la presencia de muchas prosopopeyas, donde el autor le concede a seres inanimados o sustantivos abstractos unas cualidades, tales como: «dulce sueño», «ruido temeroso y preste», «inocente pueblo», «flaco aliento», «triste caso», «nudo ciego», «triste sacrificio», «espíritu desnudo y sombra muda», «dolor rabioso» (Chang-Rodríguez, 2008, p.133-138), sorprendentemente cuenta la historia del príncipe de Campeche; Huitzel, quien con su amada Quetzal, viven apartados de las demás personas de las tierras novohispanas, hasta que los conquistadores los capturan, y al resto de los residentes, los cuales son repartidos entre todos los conquistadores: «fuimos súbitamente salteados / con un ruido temeroso y presto» (ChangRodríguez, 2008, p. 133). Sustancialmente, el contenido del poema se encuentra establecido en la conquista de las tierras novohispanas por parte de los españoles y la captura de los residentes en éstas, entre ellos, a una pareja de enamorados quienes vivían apartados de los demás.

De igual forma, así como en La fuente de la eterna juventud, el estado de ánimo del hablante no se encuentra de manera explícita en el poema, el autor novohispano Francisco de Terrazas promulga en su obra Nuevo mundo y conquista, una escenificación idónea del amor, llena de las características básicas de este sentimiento y armónica con la complejidad de la época, situándose en plena colonia, o, mejor dicho, en el asentamiento de ésta. Consecuentemente, Terrazas hace evidente su envío poético a través de la reverberación y magnificación del romanticismo en consonancia con la exposición de los valores coloniales españoles que están siendo imbricados con el costumbrismo indígena, a saber, de representar 
históricamente las relaciones sociales y amorosas no convencionales, mostrar las injusticias inexplicables y colocar en primer orden la supervivencia cultural de Quetzal y Huitzel.

En ese sentido, es pertinente anotar que, mediante unas estructuras poéticas llamadas a describir la culturalidad y la sociedad de la época colonial, Terrazas se muestra como un transmisor de romance indígena caracterizado por el idilio, incertidumbre y afán evidenciado tanto en Quetzal como en Huitzel, por consiguiente, describe acontecimientos naturales e igualmente movidos por la situación gubernativa. De esta manera, se determina que lo percibido por Terrazas se relaciona con la profundidad de las condiciones inmersas en Tabasco y Campeche, dando y concediendo una inferencia sobre su posible interpretación personal, la cual, consistiría en conceptualizar un drama, en el sentido de ampliar lo que él propone como romántico en conjunto con lo impactante que fue el proceso de conquista.

\section{La heroicidad mapuche a la manera clásica griega en las guerras del Arauco: Ercilla propone la unión de geografía y política en conjunto con lo épico.}

Siguiendo con el conjunto de descripciones literarias y dándole un análisis detallado al canto I de La Araucana de Alonso de Ercilla, se expone: una construcción estructural de 23 estrofas trabajadas con la técnica de octava real y endecasílabos, escrita con una rima encadenada consonántica, con figuras retóricas, tales como antítesis: «hará mi torpe estilo delicado» (Chang-Rodríguez, 2008, p.142), prosopopeya: «si su estrella y pronóstico se miran/ para que autoridad mi verso cobre» (Chang-Rodríguez, 2008, p. 144), y símil: «como a inmortales dioses los tenían que con ardientes rayos combatían» (Chang-Rodríguez, 2008, p. 144), este canto narra el momento en que los españoles llegan a Chile y la rebelión de los habitantes del lugar, ya que éstos, acostumbrados a vivir sin gobernadores, no permitirían que personas ajenas a sus costumbres los dominaran. Por lo tanto, su temática está encausada en la llegada de los conquistadores a Chile y la rebelión de los nativos araucanos ante ellos, negándose así al dominio de los españoles.

De este modo, y considerando lo anterior, se puede percibir que la visión de mundo que el autor plantea en su obra, se encuentra adyacente al tema de la misma: las guerras de los mapuches contra el ejército de conquista español en defensa por el Estado de Arauco. Prácticamente, Ercilla mediatiza su presencia del hecho con lo realmente histórico, produce así una combinación de epicidad de los soldados tanto indígenas como españoles, dinamiza 
la trascendencia de Chile con los objetivos militares del Imperio hispano y encierra su interpretación a: mostrar, desde su perspectiva, de forma dramática y descriptiva las peripecias de las batallas por la pertenencia de los territorios, dándole un toque trágico al fundamento poético y resaltando igualmente las fortunas paisajísticas de la región austral. En plena idea, la visión de Ercilla configura en tanto una exaltación magistral a la gente natural y aborigen del Arauco e incluso resalta que Chile es una «región antártica famosa/ de remotas naciones respetadas/ por fuerte, principal y poderosa». (Chang-Rodríguez, 2008, p. 143).

Consecuentemente, Alonso de Ercilla crea un cónclave entre lo estéticamente épico y lo funcional del belicismo, partiendo de la idea literaria griega de los guerreros y héroes idolatrados, este autor es competente cuando reconoce que Chile es una gran tierra y su gente es de armas tomar, nada sumisa y férreamente poderosa en carácter. De esta manera, se puede abordar el estado de ánimo -o su envío poético- de Ercilla, a grandes rasgos, como una proliferación de sorpresas, sí, una cadena de impactos tras impactos en el poeta, capaces de configurar a éste en un testigo de la posible guerra más sangrienta de la conquista, en el Arauco, la tierra firme de los mapuches sin dueños, políticamente anárquicos, despiadados ante cualquier extranjero cuyo propósito sea dominar. Sustancialmente, La Araucana representa estupefacción ercillana, llamada no a saturar, sino preponderar un suceso histórico sin precedentes que marca profundamente la historia de América y Europa.

A suma de lo anterior, nada que haya relatado Ercilla se mantiene en un plano de congelamiento literario, sino por el contrario, se encuentra en los vaivenes de los sucesos históricos que enmarcan fielmente lo terrorífico que fueron las guerras del Arauco. Es indispensable preguntarse, así como lo hace Bernal Herrera (1991, p. 58), «¿por qué, entonces, invertir tal esfuerzo en una guerra periférica, pudiendo escoger un tema más grandioso?», evidentemente, bien puede decirse que los acontecimientos bélicos de Chile significaron un cuadro impactante en la mente del poeta español, éste estuvo al pendiente de lo que ocurría, registró tanto la valentía de los mapuches como su heroicidad y tenacidad frente a la tremenda ambición de la maldad española, no omitió detalle alguno de lo duro y desesperante que fue para los hispanos el invadir tierras araucanas, no obstante, para Bernal Herrera (1991, p. 58) «da lo mismo narrar una guerra importante o una marginal: ambas obedecen a los mismos impulsos, reflejan las mismas pasiones y deben ser juzgadas con los mismos criterios», en tanto Bernal tiene razón, pero toda guerra, por más que comparta argumentos generales, debe analizarse y ser juzgada con base en disposiciones de carácter 
diverso y universal, debido a que se hallan otras condiciones, maneras y siluetas ideológicas que protagonizan los enfrentamientos. En este orden de ideas, todo se organiza en derredor de contrariedades causativas: Bernal Herrera (1991, p. 59) lo explica con la consigna de que «mientras el principal problema de los españoles es la codicia, el de los indios es la tendencia al comportamiento impulsivo e irracional», entendiéndose así que los dos bandos no escapan de la imperfección y por tanto ésta debe ser el estándar que sojuzgue una guerra.

\section{Imágenes recurrentes generales de los poemas}

\section{La conquista vista como un recurso déspota de los españoles}

El proceso de exploración, conquista y colonización de América está sumamente conectado con el despotismo e intransigencia empleados por parte de los españoles que, al igual que la resistencia y defensa de los pueblos indígenas para mantener su libertad, autonomía y gobierno sobre sus habitantes, tierras y recursos naturales, establecen un mapa de bandos ideológicos y políticos que se pueden ver plasmados en cada uno de los poemas escogidos, donde cada uno sus autores describen las ansias e intereses por parte de los hispanos para explorar y conocer tierras tan exuberantes como ningunas antes vistas. En vista de esto, conquistar se convirtió para ellos en un proceso esencial, por lo cual, Cruz Moyano (1999, p. 26) afirma que «conquistar a América terminó siendo un sinónimo de conocer a América, de interpretar a América, de fusionarse y hasta finalmente identificarse con ella» y, en virtud de la realización de la empresa conquistadora, se requirió de medios y fines en favor de obtener, dominar y gobernar aquellas tierras tan deseadas, por ende, teniendo en cuenta que los habitantes de la mismas no iban a vulnerarse a sí mismos ante la tentativa de los extranjeros para que éstos se apoderasen de sus pertenencias y recursos naturales, es entonces cuando los españoles se ven en la necesidad, por decirlo de esta manera, de emplear la fuerza y abuso sobre los nativos americanos, trayendo sobre ellos una gran devastación.

Trascendentalmente, Cruz Moyano (1999, p. 24) está seguro de que «no es para nadie un secreto que el principal elemento que opuso resistencia a la conquista y el vasallaje del territorio americano y sus gentes fue la misma naturaleza que se tornó poderosa e implacable», debido a estos factores y al tipo de accionar que tuvieron los colonizadores, se efectuaron grandes cantidades de muertes, abusos e injusticias por parte de los mismos que, a posteriori, hacen ver claramente que el cuadro colonizador no fue más que una déspota 
invasión en armonía con lo exponencialmente lógico: «el verdadero rostro de la conquista fue la violencia» (Cruz Moyano,1999, p. 24).

\section{Semejanzas y diferencias entre los poemas}

En este apartado, se tratarán las semejanzas y diferencias de los poemas escogidos, acompañadas de nociones fundadas en los aspectos históricos y literarios inmersos en las poetologías de Castellanos, Terrazas y Ercilla, a fin de encontrar y explicar los fundamentos poéticos de cada autor. De esta manera, se presentan:

1. Semejanzas entre La Elegía VI - Canto VII: La fuente de la eterna juventud de Juan de Castellanos, la cuarta parte de Nuevo Mundo y conquista de Francisco de Terrazas y el canto I de La Araucana de Alonso de Ercilla

A pesar de tratarse de diversos temas, los tres cantos expuestos se asemejan en el hecho de que son poemas épicos, ya que en todos ellos hay historias de conquistas, como se puede encontrar en La Elegía VI - Canto VII: La fuente de la eterna juventud de Juan de Castellanos, puesto que, en ésta, Juan Ponce de León, quería llegar al lugar cuyo nombre se encuentra en el título del mismo canto, y quería tomarlo como suyo, es decir, conquistarlo. De igual manera, se evidencian abatimientos, como en el caso del príncipe Huitzel y la princesa Quetzal, del poema Nuevo Mundo y Conquista (parte 4) de Francisco de Terrazas.

Además de eso, en los tres poemas en estudio, se reflejan guerras y admiración de los paisajes vírgenes de la época, al mismo tiempo que cada autor exalta el heroísmo de los personajes indígenas que no permiten, en cierta manera, el dominio de sus tierras y de sus personas. En tanto, se puede atestiguar lo anterior con la estupefacción de Alonso de Ercilla hacia Chile y sus residentes, en un fragmento de su obra La Araucana, mostrado a continuación:

Chile, fértil provincia y señalada

en la región antártica famosa, de remotas naciones respetada por fuerte, principal y poderosa; la gente que produce es tan granada, 
tan soberbia, gallarda y belicosa,

que no ha sido por rey jamás regida

ni a estranjero dominio sometida.

(Chang-Rodríguez, 2008, p.142)

En proporción con lo épico, otras de las similitudes de estos tres cantos, es que son de carácter expositivo, dado que en algún momento de sus escritos, cada autor saca a la luz no solamente los paisajes de la época, sino también la actitud de los residentes del lugar, por ejemplo, cuando en La fuente de la eterna juventud, Juan de Castellanos menciona: «iqué de haciendas, joyas y preseas por remozar vendieran los varones!/ ¡qué grita de hermosas y de feas anduvieran aquestas estaciones!»(Chang-Rodríguez, 2008, p.125.).

De igual forma, los cantos se asemejan en que también son de carácter histórico, pues, como su nombre lo indica, estos relatos cuentan hechos o sucesos del pasado colonial que marcaron la historia de un lugar determinado. Se puede observar estos factores en el siguiente fragmento de La Araucana de Alonso de Ercilla: «y reduciendo a su opinión gran gente/ siete ciudades prósperas fundaron: Coquimbo, Penco, Angol y Santiago, la Imperial, Villarrica, y la del Lago». (Chang-Rodríguez, 2008, p.44)

Ahora bien, se conocen las semejanzas de estos cantos, pero no las razones por las cuales, al menos dos de ellos, están estrechamente conectados: se puede decir que Francisco de Terrazas se inspiró en La Araucana de Alonso de Ercilla, para escribir Nuevo Mundo y Conquista, es por eso que en ambas obras, se logra ver cómo el héroe es exaltado en cierto punto y, además, la ambición de los españoles al querer conquistar el territorio americano, para obtener las tierras y tesoros de los residentes.

2. Diferencias entre La Elegía VI - Canto VII: La fuente de la eterna juventud de Juan de Castellanos, la cuarta parte de Nuevo Mundo y Conquista de Francisco de Terrazas y el canto I de La Araucana de Alonso de Ercilla:

Como es sabido, dentro del mundo de la literatura existen corrientes que denotan las características tanto en la forma de escribir como en la temática, en común acuerdo con las condiciones sociales y culturales de una determinada época. 
Entre las diferencias, se encuentra la contrariedad de enfoques que tiene Francisco de

Terrazas con las de Juan de Castellanos y Alonso de Ercilla, ya que el primero, influido principalmente por la corriente petrarquista, la cual, muestra las emociones y sentimientos más profundos como el amor y cariño de forma notoria. Por lo tanto, este autor se aleja un poco, pero sin dejar de lado la narración de hechos acaecidos en la importante historia de la conquista, para centrarse en la demostración de la sentimentalidad que tuvieron aquellos que sufrieron y estuvieron presentes en dicho proceso, mientras Castellanos y Ercilla, actuaron en sus poemas como expositores que van relatando aquellos acontecimientos de manera descriptiva, exaltando la exuberancia de las tierras de una forma magistral e incluso dándole un lugar al reconocimiento de los héroes colonizadores y descartando sus historias dentro de cada poema.

Además de lo anterior, en los poemas se tocan ejes centrales, los cuales permiten el desarrollo de las historias contadas en los mismos. En primera instancia, La Elegía VI - Canto VII: La fuente de la eterna juventud, obra que gira en torno o centra su historia en la fantasía, es decir, parte de una creencia mitológica por parte de los indios encontrados en la isla llamada Bímini, descubierta o vista por primera vez por Juan Ponce de León, el cual, influenciado por los rumores de la existencia de una fuente mítica y milagrosa donde se podía cobrar la revitalización de la juventud perdida, decide emprender un viaje hacía la ubicación de la misma, dejándose guiar por las creencias y costumbres de los nativos de aquel lugar, asimismo, demostrando la trascendencia que tenía sobre los españoles colonizadores la cultura e idiosincrasia de los indígenas.

Por otra parte, el eje que prima en Nuevo Mundo y Conquista de Francisco de Terrazas, es el amor, mediante éste el autor expone o narra cómo se concebía en la época de los asentamientos de las colonias, lo trágico que podía ser este sentimiento cuando se daba entre dos indígenas que, siendo separados por inescrupulosos colonizadores, los arrastran a un estado de tristeza y aflicción profunda. Sin embargo, destaca la defensa que hace dicha pareja por conseguir estar junta a pesar de los grandes inconvenientes que se presenta en ese camino. Partiendo de lo anterior, se puede afirmar que Francisco de Terrazas se distanció, no de manera imparcial de la poesía épica y descriptiva, sino que se encaminó en una poética más pura, una poética más lírica, donde deja ver su perspectiva acerca de lo romántico y dramático, ubicados en una época en donde primaban estereotipos herméticos que generaban 
cohibiciones en este ámbito. En plena idea, Terrazas presenta una relación prohibida entre los personajes que se encuentran en Nuevo mundo y conquista.

Por último, y en otro paraje, se nota que Alonso de Ercilla, toma como punto de partida la guerra para alimentar los relatos de su obra La Araucana; por su parte acude a lo bélico para elaborar los hechos acaecidos en su poema, en el marco del intento de conquista y dominio por parte de los españoles hacía los indios mapuches habitantes del Arauco en Chile, donde se desencadena una gran batalla causada por la resistencia que ponían los nativos de aquella zona, los que sufren grandes y devastadoras consecuencias tras el anterior enfrentamiento. No obstante, la perseverancia de algunos grupos por mantener a su gente y a sus tierras fuera de las manos destructoras de los impíos colonizadores, consiguieron mantener parcialmente su soberanía y libertad, lo cual destaca el autor de forma asombrosa.

\section{¿Por qué son poemas épicos, históricos, geográficos y etnográficos?}

A la pregunta que protagoniza el título, de seguro, hay multiplicidad de respuestas encaminadas a delatar los factores socioculturales. Sin embargo, delimitando esta cuestión a solo tres poemas como la Elegía VI de Juan de Castellanos -a partir de sus Elegías de Varones Ilustres de Indias-, la cuarta parte de Nuevo Mundo y conquista de Francisco de Terrazas y la famosa obra La Araucana de Alonso de Ercilla, se puede determinar si estos fragmentos poéticos son de carácter históricos-geográficos, etnográficos o románticos.

Comenzando por la Elegía VI de Castellanos, consistente en el afamado mito de la fuente de la eterna juventud e inmerso el almirante Juan Ponce de León, es completamente permisible aseverar que tal fragmento es tanto épico como histórico, puesto que esto se valida por medio de «una marcada voluntad historicista» (Restrepo, 1996, p. 201) proveniente del autor en términos de exponer ampliamente la interconexión que hay entre la historia natural del mito en sí y la apropiación fiel que hacen los conquistadores hacia ésta, así, ello demuestra igualmente lo que Restrepo (1996, p. 201) considera como «visión épica del pasado» que se enmarca con el protagonismo funcional de Ponce de León en la búsqueda del cáliz eterno, manteniendo constantes toques explicativos de la situación. Castellanos engloba su necesidad de informar sobre la leyenda maravillosa indígena, propiciando las «amalgamas de historia y poesía épica» (Restrepo, 1996, p.202), claro, no obviando, el carácter fantástico y exuberante del asunto, en un haz de descripciones móviles que no tratan «ni épica, ni lírica, 
pero sí las dos al mismo tiempo» (Restrepo Hernández, 2008, p.2), las cuales, denotan totalmente que el poeta español optó por la hibridez y decidió geopolitizar sus versos.

No tan alejado de Castellanos, pero sí independiente de éste, el mexicano -o novohispanoFrancisco de Terrazas emplea e inventa un estilo propio de exposición y relato causativo y cultural, debido a que en su poema Nuevo mundo y conquista, específicamente en su cuarta parte, trata temas idílicos en atención al amor y problematiza el bucle nativo-dominaciónromance mediante los personajes de la princesa de Tabasco, Quetzal, en conjunto con el príncipe de Campeche, Huitzel, dos enamorados atrapados en pleno asentamiento de la colonia de Nueva España. Al parecer, la propuesta poetológica de Terrazas es difundir la etnicidad a partir de la construcción de «una particular identidad novohispana, heredera del sentimiento criollo» (Cabrera Pons, 2015, p.3) dentro de los marcos del encausamiento lírico, propiedad nacional y anunciación de hechos formacionales del gobierno colonial. En ello, Terrazas, así como lo afirma Cabrera Pons (2015, p.6), «sí reconstruye la historia de un territorio geopolítico», es decir, agrega la historia, pero con la sustancia de romanticismo vivenciado y tipificado por asuntos indígenas que, a priori, cumplen un cuadro shakesperiano a la vista de Romeo y Julieta, a saber, encerrándolos en el tema de «retratar la verdad histórica, que la creación fantástica» (Cabrera Pons, 2015, p.4).

Consecuentemente, llegando al punto de inflexión de los autores anteriores, se encuentra la apetecida y famosa obra La Araucana de Alonso de Ercilla, polémica, retadora, innovadora, eminente y admirada, la misma cobra pasión y establece lineamientos historiográficos, culturales y etnográficos, así entonces, cumple con las tres características propuestas. La historia de las guerras feroces del Arauco vibra en cada letra de Ercilla, cuya poética es demostrar tres factores: primero, lo bélico y lo épico que, en palabras de Bernal Herrera (1991, p. 58), «el género épico tiene como tema favorito el bélico», dando a entender que Ercilla connotaba la figura angular de la guerra y sus reportes como puesta en escena literaria que «se remonta hasta La Ilíada» en importancia técnica discursiva y política; segundo, encausó adecuada y precisamente su discurso, al momento de darles el beneficio de la duda tanto a los araucanos como a los españoles disputándose Chile, evidenció «una concepción típica de la historiografía de las provincias americanas: nunca se tratan por separado la geografía y la historia» (Dichy-Malherme, 2012, p.90), en efecto, cumplió esa directriz de las crónicas y amplificó el panorama cultural; el tercero, teniendo en cuenta «las amalgamas de historia y poesía épica» (Restrepo, 1996, p. 202), Ercilla sí puso de relieve la 
etnografía aun citando en su poema que Chile era «tan soberbia, gallarda y belicosa/ que no ha sido por rey jamás regida/ ni a estranjero dominio sometida» (Chang-Rodríguez, 2008, p.143), denotando aquí una posible oposición anárquica por parte de los mapuches hacia los hispanos perteneciente, como lo afirma Dichy-Malherme (2012, p. 90), a «la historianatural y moral de un país». En todo sentido, lo expuesto anteriormente se concluye que tanto las poetologías de Castellanos, Terrazas como de Ercilla, tienen relación directa con los aspectos históricos, geográficos y etnográficos de la época: queda claro que «el discurso épico precede y prepara el clima de la elegía» (Restrepo, 1996, p.211), también que Nuevo mundo y conquista «cumple una función ideológica en la narración de la fundación de la Nueva España» (Cabrera Pons, 2015) y, asimismo, en La Araucana se observa «una geopolítica americana anterior a la conquista» (Dichy-Malherme, 2012, p.90), sintonizando entonces con una mirada de facto hacia la dinámica poética.

\section{Conclusión}

Después de toda esta exposición sumaria, se puede afirmar que la poetología va ligada a las funciones intelectuales del autor, a sus pensamientos transversales, visiones de tiempos específicos, instancia en los momentos inspirativos, paisajes de la naturaleza ${ }^{1}$ expresa y presente en concordancia con el romanticismo, historicismo y expansionismo de los modos de perspectivas. Específicamente, Castellanos, Terrazas y Ercilla componen una cadena de sucesos fundacionales de la Conquista Española en América, fueron testigos oculares de los acontecimientos encuadrados en la institución de la colonia hispanoamericana y sus organizaciones gubernamentales, vivenciaron los hechos causativos del choque cultural tremendo entre España e Indoamérica y, por consiguiente, filtraron a través de la poética todo lo que se les dio a conocer, creando nuevos conceptos, miradas y problemas del mundo. Armónicamente, la fantasía en Castellanos por medio de La fuente eterna de la juventud es tremendamente legendaria, el amor y sus peripecias con el sufrido drama en Terrazas con Nuevo mundo y conquista invitan a la pasión y desolación indígena, finalmente, las guerras, horrores, grandilocuencias de la naturaleza, invasión y resistencia en el Arauco chileno, se encuentran abiertamente relatadas en Ercilla con su portentosa obra La Araucana, ampliándose así, el horizonte literario y cronista de la emergente cultura criolla que, en el futuro, se convertirá en la polémica y deseada América Latina.

\footnotetext{
${ }^{1}$ Al respecto, acerca de la función de la naturaleza y la violencia, Adalberto Bolaño presenta una análisis en el texto "Los ríos del desastre en Juan Rulfo y Gabriel García Márquez” (2017), a través del cual se observa estas relaciones que podrían tener grandes significaciones en la literatura latinoamericana..
} 


\section{REFERENCIAS}

Bolaño-Sandoval, A. (2017). "Los ríos del desastre en Juan Rulfo y Gabriel García Márquez". Revista Cedotic. 2 (1). 191-216. Recuperado en: http://investigaciones.uniatlantico.edu.co/revistas/index.php/CEDOTIC/article/view/1806/3 116

Cabrera-Pons, Juan Carlos. (2015). El Nuevo mundo y conquista: El discurso literario en la construcción de una América criolla. Universidad Autónoma de Chiapas, p. p. 1-14.

Recuperado de: http://www.idaes.edu.ar/pdf_papeles/4-2\%20Cabrera.pdf

Chang-Rodríguez, Raquel. (2008). “Aquí, ninfas del sur, venid ligeras”. Voces poéticas virreinales. Madrid. Universidad de Texas, Editorial Iberoamericana, pp. 120-159.

Cruz-Moyano, D. (2012). Juan de Castellanos y su obra Elegías de Varones Ilustres de Indias a través de William Ospina. LA PALABRA, (18), p.p. 21-27. Recuperado de https://revistas.uptc.edu.co/index.php/la palabra/article/view/938S1870-

De Aguiar E Silva, Vítor. (1972). Teoría de la literatura. Madrid: Gredos.

Dichy-Malherme, Sarah. (2012). El primer canto de La Araucana: una cartografía épica de Chile. Centro Virtual Cervantes, Criticón, (115), p.p. 85-104. Recuperado de: https://cvc.cervantes.es/literatura/criticon/PDF/115/115 085.pdf

Herrera, Bernal. (1991). La Araucana: conflicto y unidad. Centro Virtual Cervantes, Criticón, (53), p.p. 57-69. Recuperado de: file:///C:/Users/hp/Downloads/053 057.pdf

Perkins, David. (2003). La explicación del cambio literario: la contextualización histórica. Literatura: teoría, historia, crítica, vol.5, p.p. 229-261. Recuperado de: http://bdigital.unal.edu.co/44520/1/45058-215932-1-SM.pdf

Restrepo, Luis Fernando. (1996). Imbricaciones de un proyecto histórico fundacional: la historia y las formas literarias en las Elegías de Varones Ilustres de Indias de Juan de Castellanos. Centro Virtual Cervantes, THESAVRVS, tomo 51, núm.2, p.p. 201-249. Recuperado de: https://cvc.cervantes.es/lengua/thesaurus/pdf/51/TH 51002001 1.pdf

Restrepo-Hernández, Iliana. (2008). La poesía de la descripción en Elegías de Varones Ilustres de Indias de Don Juan de Castellanos. Universidad Tecnológica de Cartagena, p.p. 1-13. Recuperado de:

http://www.cashflow88.com/Club_de_lectura_UTB/Elegias_de_Varones_ilustres_de_India $\underline{\text { s.pdf }}$ 